\title{
ORAL CYCLOSPORINE AS AN ALTERNATIVE FOR INITIAL STANDARD PROPHYLAXIS IN ALLOGENEIC STEM CELL TRANSPLANTATION WHEN INTRAVENOUS FORMULATION IS UNAVAILABLE
}

\author{
EUCARIO LEON-RODRIGUEZ*, MONICA M RIVERA-FRANCO
}

Stem Cell Transplantation Program, Department of Hematology and Oncology, Instituto Nacional de Ciencias Medicas y Nutricion Salvador Zubiran, Mexico City, Mexico. Email: eucarios@hotmail.com

Received: 02 May 2018, Revised and Accepted: 11 August 2018

\section{ABSTRACT}

Objective: The objective of the study was to compare the incidence of acute graft versus host disease (aGVHD) between oral and intravenous (IV) initial standard cyclosporine A (CsA) prophylaxis in a tertiary care center in Mexico.

Methods: A total of 117 consecutive patients who underwent allogeneic hematopoietic stem cell transplantations (HSCT) were retrospectively analyzed. GVHD prophylaxis consisted of CsA and methotrexate (MTX). CsA was administered IV, until 2005, when it was withdrawn from the market, and CsA was administered orally.

Results: Most of the patients were male (55\%), with a median age of 33 years (range, 15-63). 92 patients (79\%) received CsA orally, and 25 (22\%) intravenously. There were no significant differences in CsA concentrations during weeks 1, 2, 3, and 4 between the oral and IV group. From the entire cohort, 1 patient (4\%) from the IV group and 16 (17\%) from the oral group developed aGVHD, respectively. Sex, gender disparity, and HSCT source were statistically associated with aGVHD in the multivariate analysis.

Conclusions: Using oral instead of IV CsA for aGVHD prophylaxis is feasible and could be financially efficient; nonetheless, our results showed a higher incidence of aGVHD in the oral group; however, our study has limitations and further prospective studies including a larger cohort are encouraged.

Keywords: Cyclosporine A, Graft versus host disease, Allogeneic hematopoietic stem cell transplantation.

(C) 2018 The Authors. Published by Innovare Academic Sciences Pvt Ltd. This is an open access article under the CC BY license (http://creativecommons. org/licenses/by/4. 0/) DOI: http://dx.doi.org/10.22159/ajpcr.2018.v11i12.27049

\section{INTRODUCTION}

Acute graft versus host disease (aGVHD) can affect $20-60 \%$ of patients undergoing myeloablative allogeneic hematopoietic stem cell transplantations (allo-HSCT), and up to 50\% can develop clinically significant grades (>II). Using reduced-intensity conditioning regimens can lower the incidence; nonetheless, severe aGVHD in this context still occurs in up to $20 \%$. Due to its potent immunosuppressive activity, cyclosporine A (CsA) has been administered for GVHD prophylaxis since 1978 and the combination with methotrexate (MTX) is the most widely used regimen. CsA can be administered orally or intravenously, but some factors can influence oral cyclosporine bioavailability. Usually, initial dosing is administered intravenously during the $1^{\text {st }}$ month postallo-HSCT, and changed to oral when the patient is discharged. On the other hand, cyclosporine dosage usually begins at a higher dose (loading dose), with a gradual taper over time. However, administration, measuring, and dosing schedules of CsA vary between centers [1,2]. Moreover, it is important to maintain high concentration levels of CsA within the $1^{\text {st }}$ weeks after allo-HSCT, since low concentrations increase the risk of acute GVHD development $[3,4]$.

To date, there is not enough information regarding the use of oral versus intravenous (IV) CsA as initial dose for prophylaxis of aGVHD [5,6]. At the beginning of our transplantation program, intravenous (IV) CsA was administered during the inpatient period, but this formulation was discontinued in our country in 2005 making mandatory to use oral CsA instead. Our objective was to compare aGVHD incidence between oral and IV initial CsA standard prophylaxis during the $1^{\text {st }}$-month post-alloHSCT in a referral/tertiary care center in Mexico.

seventeen total of 117 consecutive patients who underwent allo-HSCT from January 2000 to 2017, and received CsA as immunosuppressive prophylaxis at the National Institute of Medical Sciences and Nutrition Salvador Zubiran in Mexico City, were retrospectively analyzed. The dataset used for this study derived from patients' information collected from the Transplantation Program records, containing all the information of the transplant procedure. Furthermore, hospital electronic and imaging records were revised. Patient data were deidentified, and to the retrospective nature of this study, our Institutional Review Board approved the usage of patients' information without informed consent

All patients received conditioning regimens and remained hospitalized until hematological and clinical recovery. The following myeloablative conditioning regimens were used: (1) Reduced BUCY, (2): Busulfan $12 \mathrm{mg} / \mathrm{kg}$, divided in 4 days ( $3 \mathrm{mg} / \mathrm{kg} /$ day, ORAL, during days $-7,-6,-5$, and -4 ) and cyclophosphamide (Cy), IV, $80 \mathrm{mg} / \mathrm{kg}$, divided in 2 days ( $40 \mathrm{mg} / \mathrm{kg} /$ day, during days -3, and -2), and (3) BUCY 2: Busulfan $16 \mathrm{mg} /$ $\mathrm{kg}$, and Cy $120 \mathrm{mg} / \mathrm{kg}$. Non-myeloablative regimens included: (1) Cy $50 \mathrm{mg} / \mathrm{kg}$ divided in 4 days, (2) Cy $50 \mathrm{mg} / \mathrm{kg}$ divided in 4 days, and ATG $30 \mathrm{mg} / \mathrm{kg}$ divided in 3 days, and (3) Fludarabine $30 \mathrm{mg} / \mathrm{msq}$ for 5 days, Cy $50 \mathrm{mg} / \mathrm{kg} /$ day divided in 4 days, and ATG $10 \mathrm{mg} / \mathrm{kg} /$ day divided in 4 days.

GVHD prophylaxis consisted of CsA and MTX. CsA was administered IV, $(1.5 \mathrm{mg} / \mathrm{kg} / 12 \mathrm{~h}$, during day-1 and adjusted to serum levels (200-300 $\mu \mathrm{g} / \mathrm{mL})$ ); in 2005 , CsA was administered orally (10 $\mathrm{mg} / \mathrm{kg}$ during day-1, and $5 \mathrm{mg} / \mathrm{kg}$ starting day 0 , adjusting according to therapeutic monitoring) as the IV formulation was withdrawn from the market. MTX was administered IV $\left(10 \mathrm{mg} / \mathrm{m}^{2} /\right.$ day on days $\left.+3,+6,+11\right)$. CsA concentration was daily measured before the administration of next dose, until the patient was discharged to maintain target concentrations of 200-300 $\mu \mathrm{g} / \mathrm{mL}$. Acute and chronic GVHD was graded around the time of diagnosis according to the established NIH criteria [7] 
Patients were dichotomized according to the route of administration of CsA. Continuous variables were described by the median and interquartile range using the frequency analysis. Categorical variables were described by frequencies and percentiles. Variables with normal distribution were compared with independent t-test or one-way ANOVA. Categorical variables were compared with the Chi-square or Fisher's exact test. Cox regression analysis was used to examine variables affecting aGVHD incidence. Logistic regression was used to correlate CsA concentrations with GVHD incidence. The probability of developing acute GVHD was depicted by calculating the cumulative incidence as competing risks. Two-sided $\mathrm{p}<0.05$ was considered significant. SPSS v.21 (IBM, Chicago, IL) was used.
A total of 117 consecutive patients were included. Most of the patients were male (55\%), with a median age of 33 years (range, 15-63). 92 patients $(79 \%)$ received CsA orally, and 25 (22\%) intravenously. Patients' characteristics are shown in Table 1, demonstrating statistically significant differences between both groups (oral vs. IV) exclusively in the HSCT source (BM 73\% vs. 92\%). Mean blood concentrations of CsA are also described in Table 1, showing that there were no significant differences in CsA concentrations during weeks 1, 2, 3, and 4 between the oral and IV group: $\mathrm{p}=0.5,0.8,0.3$, and 0.8 , respectively. Most of the patients received myeloablative conditioning regimens: Reduced BUCY $2(n=83,71 \%)$ and BUCY $2(n=2,2 \%)$. From the entire cohort, 17 patients (15\%) developed acute GVHD (Grade I in 1, Grade II in 8,

Table 1: Patient and HSCT characteristics

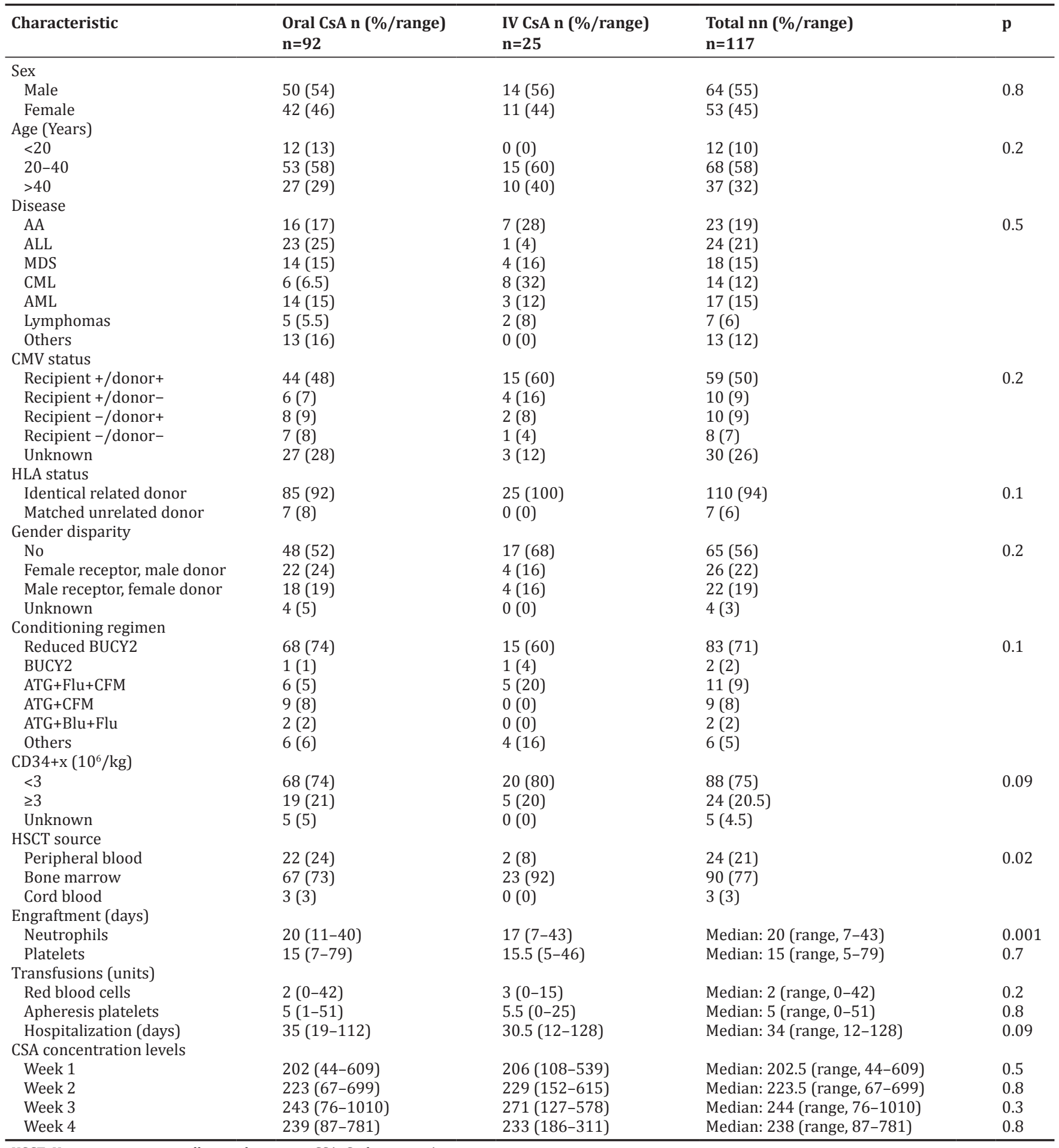

HSCT: Hematopoietic stem cell transplantations, CSA: Cyclosporine A 
Grade III in 7, and Grade IV in 1), with a median onset of 40 days (range, $12-89)$. One patient (4\%) from the IV group, and 16 patients (17\%) from the oral group; however, there was no significant association between the administration route and aGVHD incidence $(\mathrm{p}=0.09)$ (Fig. 1), or grading ( $\mathrm{p}=0.2)$. Skin was the most affected site $(\mathrm{n}=13,75 \%)$, followed by liver $(n=10)$, and intestine $(n=4)$.

Twenty eight patients (24\%) developed chronic GVHD; 5 (20\%) from the IV group, which was limited in all of them, and $23(25 \%)$ from the oral group, which was limited in $74 \%$, with a median onset of 4.9 months (range, 3.3-45.3). No statistical association between the administration route and chronic GVHD incidence or grading was found ( $\mathrm{p}=0.8$ and 0.4 , respectively)

Administration of ATG as part of the conditioning regimen $(n=30$, Table 1) showed a lower frequency of acute and chronic GVHD, 7\% and $17 \%$, respectively, compared to $17 \%$ and $27 \%$ in the myeloablative group, not showing statistically significance ( $\mathrm{p}=0.2$ for both groups); further, when excluding patients who received ATG as part of the

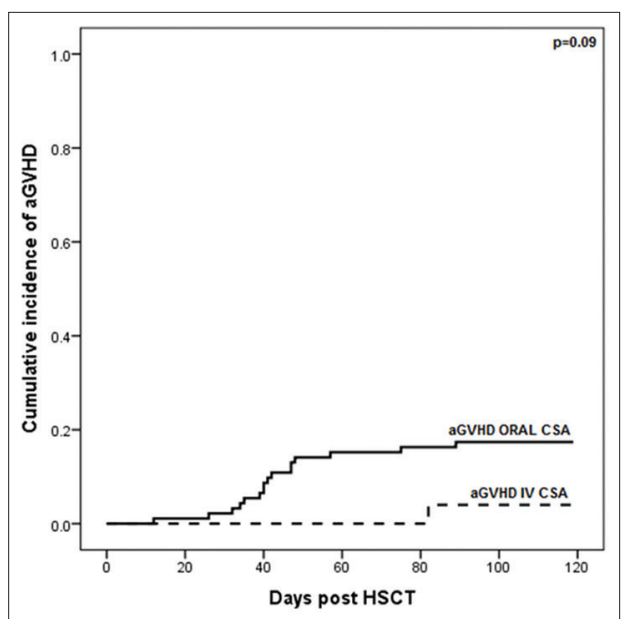

Fig. 1: Cumulative incidence of acute graft versus host disease in patients receiving intravenous versus oral cyclosporine $A$ $(p=0.09)$ conditioning regimen, no differences were observed between the administration route and the frequency of acute or chronic GVHD ( $\mathrm{p}=0.3$ and 0.5 , respectively).

Clinical variables were associated with aGVHD in a univariate analysis, and only those with $p$ value $<0.05$ were considered significant after the multivariate Cox regression. Sex, gender disparity, and HSCT source were statistically significant in the multivariate analysis (Table 2). No correlations were observed between CsA levels in week 1,2, 3, or 4 and the occurrence of acute or chronic GVHD. Moreover, no correlations were observed excluding patients receiving ATG.

One of the main obstacles to broader application of allo-HSCT is GVHD. There are standards and guidelines for GVHD prophylaxis since once established, it can be difficult to treat and can potentially impair patient's quality of life. Worldwide, prophylaxis in transplantations using myeloablative conditioning regimens consists in administering CsA with a short course of MTX [8] or mycophenolate mofetil. According to the EBMT, the initial route of administration of CsA is mostly IV [1]. From a practical standpoint, $\mathrm{CsA}$ is administered to achieve a therapeutic level, but beyond that, it is important to deliver the planned dose as per protocol. CsA pharmacokinetics may vary according to several factors, such as age, and there is no strong evidence to support applying a fixed conventional starting dose of CsA to every patient. We demonstrated that it is possible to maintain optimal mean concentrations of CsAusing both IV and oral administration during weeks 1-4, and no differences were observed.

We observed a low incidence of aGVHD in all the cohort $(15 \%$, 6.8\% Grades III-IV), compared to published literature [9], although more patients in the oral group presented aGVHD compared to IV administration (17\% and $4 \%$, respectively), it is important to highlight that since IV CsA was discontinued in our country in 2005, only 25 patients in our cohort received IV formulation, compared to 92 patients receiving oral CsA, which could explain that despite the different percentages, no statistical significance was observed.

On the other hand, chronic GVHD was also lower (oral vs. IV, 24 vs. $20 \%$, respectively) when compared to the previously published literature [10], with similar survival compared to previously reported studies.

Table 2: Univariate and multivariate analysis of factors associated with acute GVHD

\begin{tabular}{|c|c|c|c|c|c|}
\hline \multicolumn{3}{|l|}{ Univariate } & \multicolumn{3}{|c|}{ Multivariate (adjusted) Cox regression } \\
\hline Variable & OR (CI 95\%) & $\mathrm{p}$ & Variable & OR (CI 95\%) & $\mathrm{p}$ \\
\hline Sex & & & Sex & & \\
\hline Female & $1.5(0.6-3.8)$ & 0.4 & Female & $3(0.9-9.4)$ & 0.05 \\
\hline Male & 1 (Ref) & & Male & 1 (Ref) & \\
\hline Age & & & Age & & \\
\hline$\geq 40$ & $0.8(0.3-2.2)$ & 0.7 & $\geq 40$ & $0.4(0.1-1.3)$ & 0.1 \\
\hline$<40$ & 1 (Ref) & & $<40$ & 1 (Ref) & \\
\hline HLA status & & & HLA status & & \\
\hline Matched unrelated donor & $1.08(0.1-6.6)$ & 0.9 & Matched unrelated donor & - & - \\
\hline Identical related donor & 1 (Ref) & & Identical related donor & 1 (Ref) & \\
\hline Gender disparity & & & Gender disparity & & \\
\hline Yes & $2.5(1-6.3)$ & 0.06 & Yes & $3.8(1.1-13)$ & 0.02 \\
\hline No & 1 (Ref) & & No & 1 (Ref) & \\
\hline HSC source & & & HSC Source & & \\
\hline Peripheral blood & $3.7(1.5-8.9)$ & 0.005 & Peripheral blood & $4(1.3-11.6)$ & 0.01 \\
\hline Bone marrow & 1 (Ref) & & Bone marrow & 1 (Ref) & \\
\hline Conditioning regimen & & & Conditioning regimen & & \\
\hline Myeloablative & $2.5(0.6-10.6)$ & 0.2 & Myeloablative & $1.5(0.3-7.4)$ & 0.5 \\
\hline Non-myeloablative & 1 (Ref) & & Non-myeloablative & 1 (Ref) & \\
\hline Cyclosporine & & & Cyclosporine & & \\
\hline Intravenous & $0.2(0.03-1.6)$ & 0.1 & Oral & $0.3(0.04-2.5)$ & 0.2 \\
\hline Oral & 1 (Ref) & & Intravenous & 1 (Ref) & \\
\hline
\end{tabular}


Further, the median age in our cohort was relatively low (68\% $\leq 40$ years), a fact that could have contributed to our overall favorable results, along with $94 \%$ of patients having an HLA-identical sibling donor. Furthermore, the low incidence of aGVHD in both groups could have been related with the use of bone marrow as the source of the HSCT, along with the dosage reduction of our most frequently used myeloablative conditioning regimen (71\% reduced BUCY 2) [11], which could have reduced tissue damage, one of the proposed mechanisms that initiate GVHD. Although patients receiving ATG as part of their conditioning regimen had a lower frequency of both acute and chronic GVHD, no statistical significant differences were observed.

There is only one retrospective case report published in 2015 [5] showing that oral administration of CsA could prevent the occurrence of aGVHD comparable to IV administration. The authors [5] included a small cohort (48 patients), and they found differences in CsA concentrations during week 2 , which we did not observe in our practice. The authors also concluded that oral administration was economically advantageous which coincides with our observations. It is important to restrain costs while maximizing outcomes in developing countries. Since IV CsA was withdrawn from the Mexican market, its importation was not feasible nor affordable for our HSCT program; thus, oral CsA is currently preferred due to reduced costs and less invested time in nursing care.

In conclusion, although showing that oral instead of IV CsA for aGVHD prophylaxis is feasible and financial resources can be reduced in developing countries when IV formulation is not available, aGVHD incidence was higher in the oral CsA group. Thus, if possible, IV formulation should be used to further reduce GVHD in our patients. Despite including patients for almost two decades, none of our practices changed throughout the years; therefore, that is not a disadvantage for our results. Yet, we acknowledge that this study has limitations: It was performed retrospectively, including a reduced group of patients with IV CsA; therefore, further prospective studies are encouraged.

\section{ACKNOWLEDGMENTS}

We thank the non-governmental and non-profit organization "Unidos... Asociacion Pro Trasplante de MedulaOsea," in Mexico City, for facilitating most of our patients the acquisition of medications, and providing emotional support.

\section{AUTHORS' CONTRIBUTIONS}

Analyzed the data: MMRF. Wrote the first draft of the manuscript: MMRF. Contributed to the writing of the manuscript: ELR. Agree with manuscript results and conclusions: All authors. Jointly developed the structure and arguments for the paper. All authors. Made critical revisions and approved final version: ELR. All authors reviewed and approved of the final manuscript.

\section{CONFLICTS OF INTEREST}

None of the authors have conflicts of interest or competing financial interests.

\section{REFERENCES}

1. Ruutu T, van Biezen A, Hertenstein B, Henseler A, Garderet L, Passweg J, et al. Prophylaxis and treatment of GVHD after allogeneic haematopoietic SCT: A survey of centre strategies by the European group for blood and marrow transplantation. Bone Marrow Transplant 2012;47:1459-64.

2. Ruutu T, Gratwohl A, de Witte T, Afanasyev B, Apperley J, Bacigalupo A, et al. Prophylaxis and treatment of GVHD: EBMT-ELN working group recommendations for a standardized practice. Bone Marrow Transplant 2014;49:168-73.

3. Oshima K, Kanda Y, Nakasone H, Arai S, Nishimoto N, Sato H, et al. Decreased incidence of acute graft-versus-host disease by continuous infusion of cyclosporine with a higher target blood level. Am J Hematol 2008;83:226-32.

4. Izumi N, Furukawa T, Sato N, Okazuka K, Tsukada N, Abe T, et al. Risk factors for acute graft-versus-host disease after allogeneic hematopoietic stem cell transplantation: Retrospective analysis of 73 patients who received cyclosporin A. Bone Marrow Transplant 2007; 40:875-80.

5. Nygaard M, Hovgaard D, Schjødt IM, Andersen NS, Vindeløv L, Sengeløv $\mathrm{H}$, et al. Oral cyclosporine A treatment is feasible after myeloablative conditioning in allogeneic hematopoietic stem cell transplantation. J Clin Pharm Ther 2015;40:358-61.

6. Inoue Y, Saito T, Ogawa K, Nishio Y, Kosugi S, Suzuki Y, et al. Pharmacokinetics of cyclosporine a conversion from twice-daily infusion to oral administration in allogeneic hematopoietic stem cell transplantation. Am J Ther 2014;21:377-84.

7. Vigorito AC, Campregher PV, Storer BE, Carpenter PA, Moravec CK, Kiem HP, et al. Evaluation of NIH consensus criteria for classification of late acute and chronic GVHD. Blood 2009;114:702-8.

8. Ringdén O, Horowitz MM, Sondel P, Gale RP, Biggs JC, Champlin RE, et al. Methotrexate, cyclosporine, or both to prevent graft-versus-host disease after HLA-identical sibling bone marrow transplants for early leukemia? Blood 1993;81:1094-101.

9. Jagasia MH, Greinix HT, Arora M, Williams KM, Wolff D, Cowen EW, et al. National institutes of health consensus development project on criteria for clinical trials in chronic graft-versus-host disease: I. The 2014 diagnosis and staging working group report. Biol Blood Marrow Transplant 2015;21:389-4010.

10. Rubio MT, Labopin M, Blaise D, Socié G, Contreras RR, Chevallier P, et al. The impact of graft-versus-host disease prophylaxis in reducedintensity conditioning allogeneic stem cell transplant in acute myeloid leukemia: A study from the acute leukemia working party of the European group for blood and marrow transplantation. Haematologica 2015;100:683-9.

11. Leon Rodriguez E, Rivera Franco MM, Perez Alvarez SI. Reduced BUCY 2 and G-CSF-primed bone marrow associates with low graftversus-host-disease and transplant-related mortality in allogeneic HSCT. Ann Hematol 2017;96:1525-31. 